\title{
Triptolide blocks the STAT3 signaling pathway through induction of protein tyrosine phosphatase SHP-1 in multiple myeloma cells
}

\author{
JI-HUN KIM ${ }^{1}$ and BYOUNGDUCK PARK ${ }^{2}$ \\ ${ }^{1}$ College of Pharmacy, Chungbuk National University, Cheongju, North Chungcheong 28160; ${ }^{2}$ College of Pharmacy, \\ Keimyung University, Daegu 704-701, Republic of Korea
}

Received September 22, 2016; Accepted August 25, 2017

DOI: $10.3892 / \mathrm{ijmm} .2017 .3122$

\begin{abstract}
Triptolide, an active component extracted from the medicinal plant Tripterygium wilfordii Hook F., has been used to treat various diseases, including lupus, cancer, rheumatoid arthritis and nephritic syndrome. The present study investigated the effects of triptolide on multiple myeloma using western blotting and an electrophoretic mobility shift assay. Triptolide was found to suppress the inducible and constitutive activation of signal transducer and activator of transcription 3 (STAT3), which is closely associated with inflammation and tumorigenesis. Triptolide also inhibited the DNA binding of STAT3. This correlated with the downregulation of Src kinase and Janus kinase 1 and 2, and with the upregulation of protein tyrosine phosphatase non-receptor type 6 (also known as SHP-1). In addition, triptolide downregulated the expression of the STAT3-regulated antiapoptotic (Bcl-xL and myeloid cell leukemia-1), proliferative (cyclin D1), and angiogenic (vascular endothelial growth factor) genes, suggesting that triptolide can induce apoptosis of tumor cells. These results suggest that triptolide may be a potential therapeutic anticancer agent for the prevention and treatment of multiple myeloma; thus further in-depth investigations into its efficacy and toxicity are warranted.
\end{abstract}

\section{Introduction}

Multiple myeloma (MM), also known as plasma cell myeloma, myelomatosis or Kahler's disease (1), is a cancer of plasma cells (the white blood cells that produce antibodies), and is considered

Correspondence to: Dr Byoungduck Park, College of Pharmacy, Keimyung University, 1095 Dalgubeoldaero, Dalseo-Gu, Daegu 704-701, Republic of Korea

E-mail: bdpark@kmu.ac.kr

Abbreviations: STAT3, signal transducer and activator of transcription 3; JAK, Janus kinase; SHP-1, protein tyrosine phosphatase non-receptor type 6; Mcl-1, myeloid cell leukemia-1; VEGF, vascular endothelial growth factor; IL-6, interleukin-6; PARP, poly(ADP-ribose) polymerase; MM, multiple myeloma

Key words: triptolide, multiple myeloma, signal transducer and activator of transcription 3, Janus kinase, SHP-1 to be incurable (2). The incidence of MM is $\sim 4 / 100,000$ and it accounts for $10 \%$ of all hematological malignancies (3). The treatment of MM is complex due to rapid advances in stem cell transplantation, medications and supportive care, which have improved the survival times of MM patients over the past 30 years (4). The principal treatments include stem cell (bone marrow) transplantation, non-chemotherapeutic drugs that target cancer cells, standard chemotherapeutic drugs, and corticosteroids (5). However, despite various treatment options for MM, advanced combination therapies with effective agents are required for the efficient treatment of the disease in the first-line and relapsed settings, and this has resulted in the development of novel agents (6,7).

Traditional Chinese medicine (TCM) is considered to be an important source of therapies for various diseases. In 2015, a Chinese scientist won the Nobel Prize for her work in drug development from TCM; indeed, numerous drug candidate compounds from TCM are under investigation (8). Triptolide is a diterpenoid epoxide that can be isolated from the traditional Chinese medicinal herb Tripterygium wilfordii Hook F., which is used to treat inflammatory and autoimmune diseases (9). Following the initial identification of triptolide in 1972, in vivo and in vitro experiments have revealed it to exhibit a variety of bioactivities, including immunosuppression and antiinflammatory effects $(10,11)$. Triptolide has a complex mechanism of action, which involves inhibition of transcription factor nuclear factor $\kappa \mathrm{B}$ $(\mathrm{NF}-\mathrm{\kappa B})$ activation $(12,13)$, suppression of the production of prostaglandin $E_{2}$, and reduction of cytokine levels $(13,14)$.

In addition to the aforementioned activities, it was recently reported that triptolide has antitumor effects in pancreatic, gastric, breast, adrenal and thyroid cancer, as well as neuroblastoma (1,15-19). Likewise, a number of studies on the effects of triptolide on various types of cancer cells, including MM, are currently underway. Although there have been numerous attempts to explain the molecular mechanisms underlying the effect of triptolide, the mechanism in MM cells remains unclear. It has been proposed that triptolide induces epigenetic alterations via the regulation of histone methylation (20), and induces apoptosis via the activation of caspases- $8,-9$ and -3 (cysteine proteases) in MM cells (21). However, a greater understanding of its mechanism of action in MM cells is necessary in order to develop novel anticancer drugs from triptolide, due to its potential multi-organ toxicity and narrow therapeutic window. 
Notably, triptolide inhibits the Janus kinase (JAK)2 pathway in myeloproliferative disorder cells, which is a similar disease to MM (22), and it inhibits the JAK1/signal transducer and activator of transcription 3 (STAT3) and JAK2/STAT3 pathways in colon cancer cells and in a rat neuropathic pain model, respectively $(23,24)$. STATs consist of a family of six transcription factors that regulate tumor development (25). Ligand-induced activation of cell-surface cytokine receptors activates the JAK family, which phosphorylates and activates latent cytoplasmic STAT3 protein to form an active dimer (26). Activated STAT3 translocates to the nucleus and induces transcription of STAT3-regulated genes (26). Several cytokines, including IL-6 (27), transforming growth factor- $\alpha$ (28) and epidermal growth factor (EGF) (27) have been shown to activate STAT3. Numerous studies have proposed that the activation of STAT3 can suppress apoptosis, and promote proliferation, angiogenesis, chemoresistance and inflammation (29-32). Thus, the STAT3 pathway must be considered to gain an understanding of oncogenesis (25). Therefore, in the present study, the effect of triptolide on MM cells via the JAK and JAK2/STAT3 pathways was investigated.

The present study aimed to investigate the effects of triptolide on the STAT3 activation pathway and the underlying mechanism in MM cells. The structure of triptolide is shown in Fig. 1. The effect of triptolide on constitutive and IL-6-induced STAT3 activation was evaluated. The effect of triptolide on STAT3-mediated gene products associated with cellular proliferation, survival and apoptosis was also investigated. Triptolide was found to suppress STAT3 activation by activating protein tyrosine phosphatase non-receptor type 6 (SHP-1), and downregulated the expression of STAT3-regulated antiapoptotic, proliferative and angiogenic proteins.

\section{Materials and methods}

Materials. A 50-mM solution of triptolide with purity $>95 \%$ was kindly provided by Dr Aggarwal at MD Anderson Cancer Center (Houston, TX, USA). Hoechst 33342, 3-(4,5-dimethylthiazol-2-yl)-2,5-diphenyltetrazolium bromide (MTT), Tris, glycine, $\mathrm{NaCl}, \mathrm{SDS}$, and bovine serum albumin (BSA) were purchased from Sigma-Aldrich (Merck Millipore, Darmstadt, Germany). RPMI-1640 medium, fetal bovine serum (FBS), $0.4 \%$ trypan blue vital stain, and antibiotic/antimycotic mixture were purchased from Invitrogen (Thermo Fisher Scientific, Inc., Waltham, MA, USA). The rabbit polyclonal anti-STAT3 antibody (\#sc-482) and mouse monoclonal antibodies against phospho (p)-STAT3 (Tyr-705; \#sc-8059), Bcl-xL (\#sc-8392), SHP-1 (\#sc-7289), cyclin D1 (\#sc-753), procaspase-3 (\#sc-373730), JAK2 (\#sc-278), VEGF (\#sc-53462), Mcl-1 (\#sc-53951) and poly(ADP-ribose) polymerase (PARP; \#sc-7150) were purchased from Santa Cruz Biotechnology, Inc. (Santa Cruz, CA, USA). The horseradish peroxidase (HRP)-conjugated goat anti-rabbit antibody (\#1662408) was purchased from Bio-Rad Laboratories, Inc. (Hercules, CA, USA). Antibodies against phospho-specific Src (Tyr-416; \#2101S), Src (\#2108), phospho-specific JAK1 (Tyr-1022/1023; \#3331S), p-JAK2 (\#3771S), and JAK1 (\#3332) were obtained from Cell Signaling Technology, Inc. (Beverly, MA, USA). The HRP-conjugated goat anti-mouse antibody (\#554002) was purchased from Transduction Laboratories (Lexington,

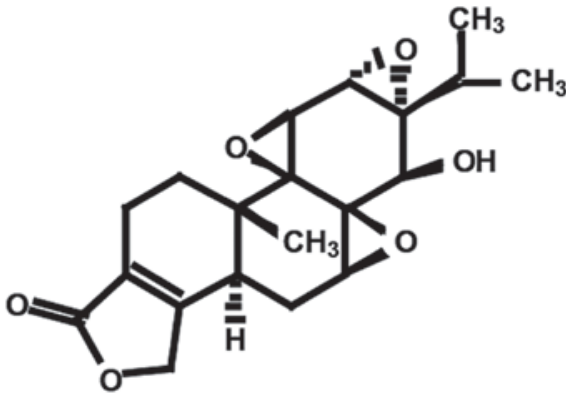

Figure 1. Chemical structure of triptolide (molecular weight, 360.4)

KY, USA). Bacteria-derived recombinant human IL-6 was obtained from Novartis Pharmaceuticals (East Hanover, NJ, USA).

Cell lines. The human MM cell lines U266 and dexamethasone-sensitive MM.1S were purchased from the American Type Culture Collection (ATCC; Manassas, VA, USA). Cell lines were cultured in RPMI-1640 medium containing $10 \%$ FBS and $1 \mathrm{X}$ antibiotic/antimycotic solution. Cells were maintained at $37^{\circ} \mathrm{C}$ in an atmosphere of $5 \% \mathrm{CO}_{2}, 95 \%$ air.

Western blot analysis. For the detection of p-STAT3 (Tyr-705) and STAT3 proteins, triptolide-treated whole-cell extracts were lysed in lysis buffer [20 mM Tris (pH 7.4), $250 \mathrm{mM} \mathrm{NaCl}$, 2 mM EDTA (pH 8.0), 0.1\% Triton X-100, $0.01 \mathrm{mg} / \mathrm{ml}$ aprotinin, $0.005 \mathrm{mg} / \mathrm{ml}$ leupeptin, $0.4 \mathrm{mM}$ phenylmethylsulfonyl fluoride, and $4 \mathrm{mM} \mathrm{Na}_{3} \mathrm{VO}_{4}$ ]. Lysates were then centrifuged at $16,025 \mathrm{x} \mathrm{g}$ for $10 \mathrm{~min}$ to remove insoluble material. The extracted proteins were resolved on a $7.5 \%$ SDS polyacrylamide gel. Following electrophoresis, the proteins were electrotransferred to a nitrocellulose membrane, blocked with $5 \%$ non-fat milk, and probed with anti-p-STAT3 antibodies (1:500) and anti-STAT3 antibodies $(1: 1,000)$ overnight at $4^{\circ} \mathrm{C}$. The blot was then washed, exposed to HRP-conjugated secondary antibodies $(1: 10,000)$ at room temperature for $1 \mathrm{~h}$, and finally examined by enhanced chemiluminescence (Amersham Biosciences, Piscataway, NJ, USA).

To detect the expression of STAT3-regulated proteins and caspase-3, U266 cells $\left(2 \times 10^{6} / \mathrm{ml}\right)$ were treated with $60 \mu \mathrm{M}$ triptolide for the indicated times. The cells were then washed and proteins were extracted by incubation for $30 \mathrm{~min}$ on ice in $0.05 \mathrm{ml}$ of buffer containing $20 \mathrm{mM}$ HEPES ( $\mathrm{pH} 7.4$ ), $2 \mathrm{mM}$ EDTA, $250 \mathrm{mM} \mathrm{NaCl}, 0.1 \%$ Nonidet P-40, $2 \mu \mathrm{g} / \mathrm{ml}$ leupeptin, $2 \mu \mathrm{g} / \mathrm{ml}$ aprotinin, $1 \mathrm{mM}$ phenylmethylsulfonyl fluoride, $0.5 \mu \mathrm{g} / \mathrm{ml}$ benzamidine, $1 \mathrm{mM}$ DTT, and $1 \mathrm{mM}$ sodium orthovanadate. The lysate was centrifuged, and the supernatant was collected. Whole-cell protein extract $(50 \mu \mathrm{g})$ was resolved by $10 \%$ SDS-PAGE; electrotransferred onto a nitrocellulose membrane; blotted with antibodies against Bcl-xL (1:500), myeloid cell leukemia-1 (Mcl-1; 1:500), cyclin D1 $(1: 1,000)$, VEGF $(1: 1,000)$, and caspase- $3(1: 1,000)$ overnight at $4^{\circ} \mathrm{C}$. The blots were washed, exposed to HRP-conjugated goat anti-mouse antibodies for $1 \mathrm{~h}$ at room temperature, and then detected by enhanced chemiluminescence.

Electrophoretic mobility shift assay (EMSA). DNA binding of STAT3 was analyzed by EMSA using a ${ }^{32} \mathrm{P}$-labeled high-affinity 
A
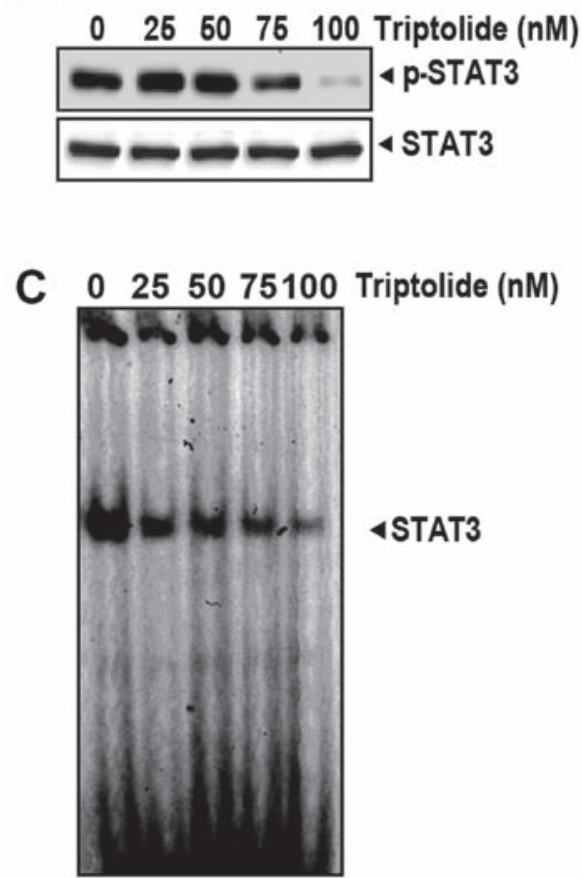

7.2 3.94.3 2.71.0 Fold

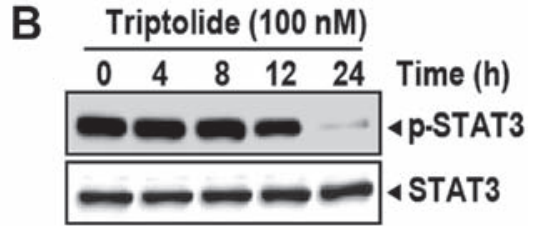

D $\begin{array}{llllll}0 & 3 & 6 & 12 & 24 & \text { Triptolide (h) }\end{array}$

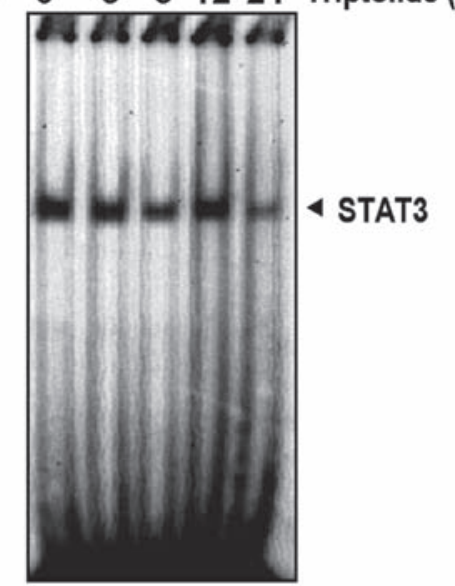

4.23.9 2.73.21.0 Fold

Figure 2. Triptolide inhibits constitutively active STAT3 in U266 cells. (A) Triptolide suppresses p-STAT3 levels in a dose-dependent manner. U266 cells $\left(2 \times 10^{6} / \mathrm{ml}\right)$ were treated with the indicated concentrations of triptolide for $24 \mathrm{~h}$, after which whole-cell extracts were prepared, and $30 \mu \mathrm{g}$ of protein was resolved on 7.5\% SDS-PAGE gel, electrotransferred onto nitrocellulose membranes and probed for p-STAT3. (B) Triptolide suppresses p-STAT3 levels in a time-dependent manner. U266 cells $\left(2 \times 10^{6} / \mathrm{ml}\right)$ were treated with $100 \mathrm{nM}$ triptolide for the indicated durations and analyzed for p-STAT3 levels. (C) Triptolide suppresses STAT3 DNA binding in a dose-dependent manner. U266 cells $\left(2 \times 10^{6} / \mathrm{ml}\right)$ were treated with the indicated concentrations of triptolide for $24 \mathrm{~h}$ and analyzed for nuclear STAT3 levels by EMSA. (D) U266 cells $\left(2 \times 10^{6} / \mathrm{ml}\right)$ were treated with $100 \mathrm{nM}$ triptolide for the indicated durations and analyzed for nuclear STAT3 levels by EMSA. STAT3, signal transducer and activator of transcription 3; p-, phospho-; EMSA, electrophoretic mobility shift assay.

sis-inducible element probe, as previously described (33). Briefly, nuclear extracts were prepared from $\gamma$-T3-treated cells and incubated with high-affinity sis-inducible element probes (5'-CTTCATTTCCCGTAAATCCCTAAAGCT-3' and 5'-AGCTTTAGGGATTTACGGGAAATGA-3'). The DNA-protein complexes that formed were separated from free oligonucleotides on $5 \%$ native polyacrylamide gels. The dried gels were visualized, and the radioactive bands were quantitated with a Storm 820 Phosphorimager and ImageQuant TL 7.0 (both from Amersham; GE Healthcare Life Sciences, Little Chalfont, UK).

Western blot analysis of PARP degradation. Triptolide-induced apoptosis was examined by proteolytic cleavage of PARP. Briefly, cells $\left(2 \times 10^{6} / \mathrm{ml}\right)$ were treated with $60 \mu \mathrm{M}$ triptolide for the indicated times at $37^{\circ} \mathrm{C}$. The cells were then washed and subjected to protein extraction by incubation for $30 \mathrm{~min}$ on ice in $0.05 \mathrm{ml}$ buffer containing $20 \mathrm{mM}$ HEPES ( $\mathrm{pH} 7.4$ ), $2 \mathrm{mM}$ EDTA, $250 \mathrm{mM} \mathrm{NaCl}, 0.1 \%$ Nonidet P-40, $2 \mathrm{ng} / \mathrm{ml}$ leupeptin, $2 \mathrm{ng} / \mathrm{ml}$ aprotinin, $1 \mathrm{mM}$ phenylmethylsulfonyl fluoride, $0.5 \mathrm{ng} / \mathrm{ml}$ benzamidine, $1 \mathrm{mM}$ DTT, and $1 \mathrm{mM}$ sodium orthovanadate. The lysate was centrifuged, and the supernatant was collected. Protein extract $(40 \mu \mathrm{g})$ was resolved by $10 \%$ SDS-PAGE, electrotransferred onto a nitrocellulose membrane, blotted with anti-PARP antibody, overnight at $4^{\circ} \mathrm{C}$. The blot was washed, exposed to HRP-conjugated goat anti-mouse antibody for $1 \mathrm{~h}$ at room temperature, and then detected by enhanced chemiluminescence.

\section{Results}

Triptolide downregulates constitutive STAT3 activation in a dose-and time-dependent manner. Whether triptolide regulates constitutive STAT3 activation in MM cells was examined by determination of STAT3 phosphorylation. Whole-cell extracts were prepared from U266 cells pretreated for $6 \mathrm{~h}$ with various concentrations of triptolide and STAT3 phosphorylation was examined by western blot analysis using an anti-p-STAT3 (Tyr705) antibody. Triptolide inhibited the constitutive activation of STAT3 in U266 cells, with maximum inhibition at $100 \mathrm{nM}$ (Fig. 2A). Under these conditions, triptolide had no effect on the STAT3 protein level (Fig. 2A). The incubation time required for suppression of STAT3 activation by triptolide was also examined in U266 cells. Triptolide inhibited the activation of STAT3 in a time-dependent manner, with maximum inhibition occurring at $24 \mathrm{~h}$, again with no effect on the STAT3 protein level (Fig. 2B).

Triptolide inhibits DNA binding of STAT3. It was investigated whether triptolide reduces the DNA-binding activity of STAT3 based on the fact that phosphorylation of STAT3 regulates gene transcription via its dimerization, nuclear translocation and DNA binding. An EMSA using nuclear extracts of U266 cells was performed; the results indicated that triptolide decreased the DNA-binding activity of STAT3 in a dose-dependent (Fig. 2C) and time-dependent (Fig. 2D) manner. Thus, triptolide is capable of eliminating the DNA-binding ability of STAT3. 

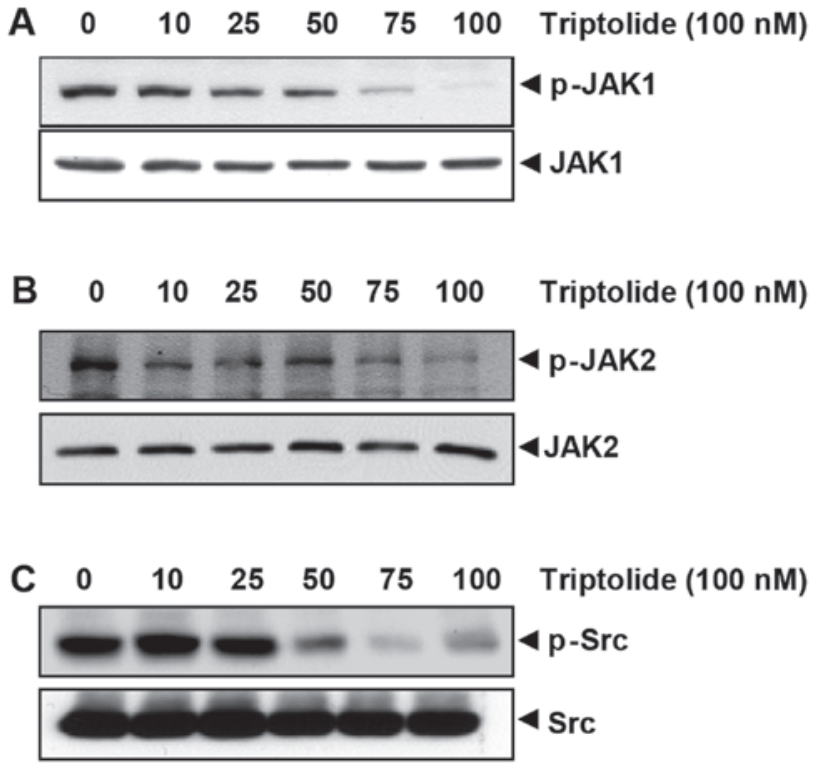

Figure 3. Triptolide downregulates constitutively active JAK1, JAK2 and Src. Triptolide downregulates (A) p-JAK1 expression, (B) p-JAK2 expression, and $(\mathrm{C}) \mathrm{p}$-Src levels in a dose-dependent manner. In all experiments, U266 cells $\left(2 \times 10^{6} / \mathrm{ml}\right)$ were treated with the indicated doses of triptolide for $24 \mathrm{~h}$, after which whole-cell extracts were prepared, and $40 \mu \mathrm{g}$ of those extracts were resolved by SDS-PAGE, electrotransferred onto nitrocellulose membranes, and probed with p-JAK1, p-JAK2 and p-Src, respectively. JAK, Janus kinase; p-, phospho-.

Triptolide suppresses constitutive activation of Src, JAK1, and JAK2. STAT3 may be constitutively activated by soluble tyrosine kinases of the Src kinase (34) and JAK (35) families. Therefore, the effects of triptolide on the constitutive activation of Src kinase, JAK1 and JAK2 in U266 cells were investigated. Triptolide was found to suppress the constitutive phosphorylation of JAK1 (Fig. 3A) and JAK2 (Fig. 3B) in a dose-dependent manner, while the total levels of JAK1 and JAK2 remained unchanged under the same conditions (Fig. 3A and B). As shown in Fig. 3C, triptolide suppressed the constitutive phosphorylation of Src kinase in a dose-dependent manner, while the total Src kinase protein levels remained unchanged (Fig. 3C).

Triptolide inhibits inducible STAT3 phosphorylation in MM cells. Because STAT3 is also activated by phosphorylation at tyrosine residues in response to IL-6 (27), it was investigated whether triptolide could inhibit IL-6-induced STAT3 phosphorylation in MM.1S cells, which lack constitutively active STAT3. As shown in Fig. 4A, IL-6 induced phosphorylation of STAT3 in a dose-dependent manner. IL-6-induced STAT3 phosphorylation was suppressed by triptolide in a dose-dependent manner (Fig. 4B). A triptolide concentration $>50 \mathrm{nM}$ was sufficient to suppress IL-6-induced STAT3 phosphorylation.

Triptolide induces the expression of SHP-1. SHP-1, a non-receptor-type protein tyrosine phosphatase, is known to negatively regulate the STAT3 signaling pathway $(36,37)$. Therefore, it was examined whether the inhibition of STAT3 phosphorylation by triptolide was due to the increased expression of SHP-1. As shown in Fig. 5A, triptolide upregulated SHP-1 expression in a time-dependent manner.
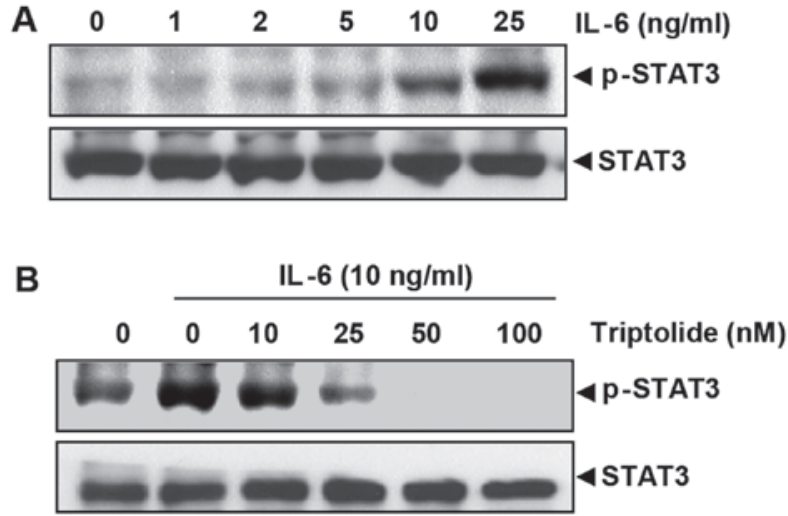

Figure 4. Triptolide downregulates IL-6-induced p-STAT3. (A) IL-6 induces p-STAT3 levels in a dose-dependent manner. MM.1S cells $\left(2 \times 10^{6} / \mathrm{ml}\right)$ were treated with the indicated doses of IL-6 for $30 \mathrm{~min}$. (B) Triptolide downregulates IL-6-induced p-STAT3 levels in a dose-dependent manner. MM.1S cells $\left(2 \times 10^{6} / \mathrm{ml}\right)$ were treated with the indicated doses of triptolide for $24 \mathrm{~h}$ and then stimulated with IL-6 $(10 \mathrm{ng} / \mathrm{ml})$ for $30 \mathrm{~min}$. Whole cells were then prepared and analyzed for p-STAT3 by western blotting. IL-6, interleukin 6; p-, phospho-; STAT3, signal transducer and activator of transcription 3.

Triptolide downregulates the expression of genes associated with cell survival, proliferation, and angiogenesis. The expression of the antiapoptotic proteins Mcl-1 and Bcl-xL, the cell cycle regulator protein cyclin D1, and the angiogenic protein VEGF, all of which have been reported to be regulated by STAT3 $(25,38)$, were downregulated by triptolide treatment (Fig. 5B). Triptolide downregulated the expression of these proteins in a time-dependent manner, with maximum suppression at $24 \mathrm{~h}$ after the beginning of treatment (Fig. 5B).

Triptolide causes caspase-3 activation and PARP cleavage. As caspase-3 is critically involved in the regulation of antiapoptotic proteins (39) and VEGF (40), it was determined whether triptolide could activate caspase-3. Treatment of U266 cells with $100 \mathrm{nM}$ triptolide induced caspase-3-dependent cleavage of a $118-\mathrm{kDa}$ PARP protein into an $87-\mathrm{kDa}$ fragment in a time-dependent manner (Fig. 5C).

\section{Discussion}

The Chinese herb T. wilfordii has been used for centuries as a traditional medicine for treating fever, chills and edema. Triptolide, a component extracted from T. wilfordii, has been intensively researched in recent years as it exhibits potent antitumor activity in various cancerous cells, such as human promyelocytic leukemia, T cell lymphoma, human hepatocellular carcinoma, cervical adenocarcinoma, pancreatic carcinoma, oral cancer cell and cholangiocarcinoma (41-43). However, triptolide has a serious drawback as an antitumor agent: Its toxicity (44). For this reason, the mechanism of action of triptolide in cancerous cells must be determined, as this would allow its toxicity to be reduced through chemical modification.

STAT3 is an important signaling pathway that has been associated with inflammation, survival, proliferation, chemoresistance, and angiogenesis (26). The results of the present study indicated that triptolide suppressed the phosphorylation of JAK1 and JAK2, which are upstream regulators of STAT3. Two STAT3 activation pathways were considered: i) IL-6-induced 
A

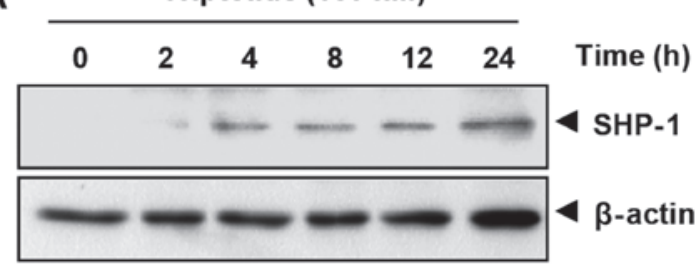

B

B

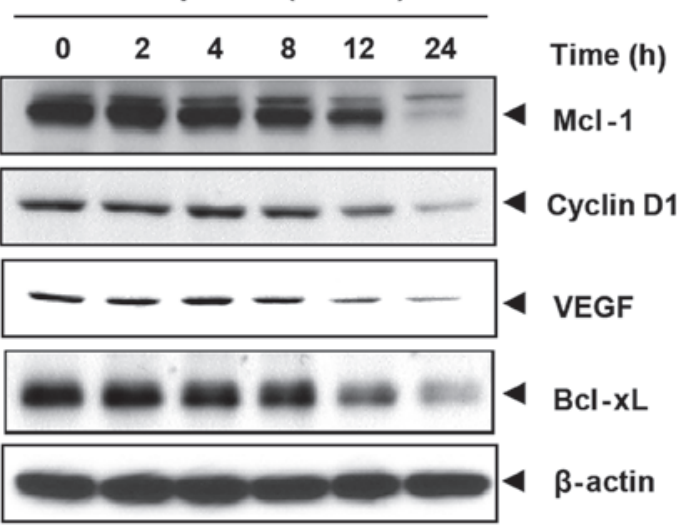

C

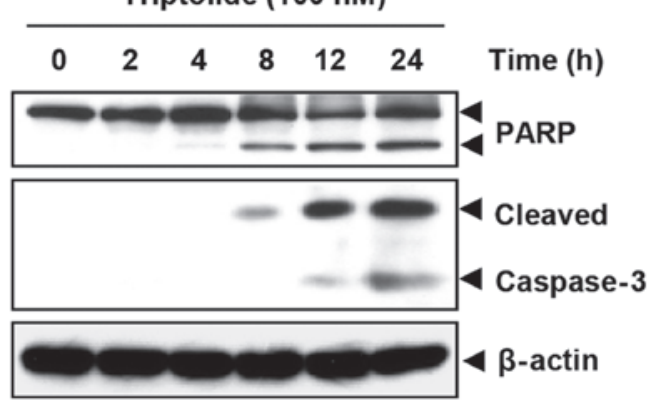

Figure 5. Triptolide upregulates SHP-1 and downregulates STAT3-regulated antiapoptotic proteins. (A) Triptolide induces the expression of SHP-1 protein in U266 cells. U266 cells $\left(2 \mathrm{X} 10^{6} / \mathrm{ml}\right)$ were treated with triptolide $(100 \mathrm{nM})$ for the indicated times. Whole-cell extracts were prepared, and $40 \mu \mathrm{g}$ of those extracts were resolved by $10 \%$ SDS-PAGE, electrotransferred onto nitrocellulose membranes, and probed with anti-SHP-1 antibody. (B) Triptolide suppresses STAT3-regulated gene products. U266 cells $\left(2 \times 10^{6} / \mathrm{ml}\right)$ were treated with $100 \mathrm{nM}$ triptolide for the indicated time intervals. Whole cell extracts were prepared, $40 \mu \mathrm{g}$ of those extracts were resolved by $10 \%$ SDS-PAGE and probed against Mcl-1, cyclin D1, VEGF and Bcl-xL antibodies. (C) Triptolide induces caspase-3-dependent PARP cleavage. U266 cells were treated with $100 \mathrm{nM}$ triptolide for the indicated times, and whole cell extracts were prepared, separated by SDS-PAGE and subjected to western blot analysis with anti-caspase- 3 and anti-PARP antibodies. In all experiments, the same blots were stripped and reprobed with anti- $\beta$-actin antibody to verify equal protein loading. SHP-1, protein tyrosine phosphatase non-receptor type 6; STAT3, signal transducer and activator of transcription 3; Mcl-1, myeloid cell leukemia-1; VEGF, vascular endothelial growth factor; PARP, poly(ADP-ribose) polymerase.

STAT3 activation via the IL-6/JAK/STAT3 cell signaling pathway, in which IL-6 binding to its receptor leads to phosphorylation of JAK, and phosphorylated JAK sequentially induces STAT3 phosphorylation; and ii) constitutive STAT3 activation involving various protein kinases $(26,45,46)$. The IL-6/JAK/STAT3 signaling pathway serves a critical role in the growth, invasion and metastasis of cancerous cells (47). Constitutively active STAT3 is also important in the survival and proliferation of myeloma, as $\sim 48 \%$ of MM patients have a constitutively active form of STAT3 (48). Regarding the mechanisms of STAT3 inhibition, it was observed in the present study that triptolide inhibited IL-6-induced and constitutive STAT3 activation in MM cells. It was also demonstrated that the mechanism of action of triptolide involves inhibition of induction of SHP-1, as well as activation of JAK1, JAK2 and c-Src. This is closely associated with the inhibition of the expression of various STAT3-regulated proteins and the induction of apoptosis in MM cells.

SHP-1, a negative regulator of the JAK/STAT signaling pathway, is hypermethylated in 79\% of MM patients (46), and demethylation of SHP-1 decreases STAT3 activation (49). In the present study, it was demonstrated that triptolide could induce SHP-1 expression, suggesting that the induction of SHP-1 may have inhibited STAT3 activation. Abnormal methylation of suppressor of cytokine signaling 1 , another regulator of the JAK/STAT3 signaling pathway, has also been observed in MM patients (50). However, this was not considered in the present study, as methylation of this gene is not strongly correlated with the clinical outcome of MM patients (50).

The present study also demonstrated that triptolide can suppress the activation of Src. Phosphorylation of Src serves a critical role in tumor cell survival. The majority of Src-transformed cell lines have persistently activated STAT3 and dominant-negative STAT3 blocks transformation (51). Furthermore, constitutive STAT3 activation has been implicated in the increased resistance to apoptosis, which leads to radiation resistance and chemoresistance (51). This may be mediated by the expression of the STAT3-regulated gene products including Bcl-xL, Mcl-1, and cyclin D1. Antiapoptotic proteins such as Bcl-xL and Mcl-1 inhibit the induction of cell death by various chemotherapeutic drugs, in parallel with an increase in chemoresistance (52). The present study demonstrated that triptolide downregulated Bcl-xL, Mcl-1 and cyclin D1, which implies that the suppression of STAT3 activation by triptolide may facilitate the apoptosis of MM cells. It was also found that triptolide downregulated the expression of VEGF, which is involved in angiogenesis of cancer cells, suggesting that triptolide may exert an antiangiogenic effect by downregulating VEGF.

Triptolide was previously reported to inhibit the transcription factor, NF- $\kappa B(21)$. However, it is unclear whether the inhibition of NF- $\mathrm{KB}$ activation is linked to the inhibition of STAT3 activation by triptolide. NF- $\mathrm{BB}$ and STAT3 are activated by different cytokines; for example, tumor necrosis factor is a major activator of NF- $\mathrm{BB}$, whereas IL- 6 activates STAT3. However, notably, JAK activation has been reported to regulate both STAT3 and NF- $\kappa$ B activation (53). Therefore, triptolide is a potent chemotherapeutic agent targeting JAK regulation, which regulates NF- $\mathrm{\kappa B}$ and STAT3 activation.

Triptolide has been widely used in East Asia for centuries for the treatment of inflammatory and autoimmune diseases, and the antitumor activity of triptolide has been investigated in various cancer cell types. The present study demonstrated that triptolide inhibits both inducible and constitutive STAT3 activation in MM cells, suggesting that it suppresses tumor cell survival, proliferation and angiogenesis. Although several barriers to the clinical use of triptolide remain to be overcome, further development of triptolide derivatives and clinical studies may result in the development of novel anticancer agents. 


\section{Acknowledgements}

This study was supported by the Basic Science Research Program through the National Research Foundation of Korea (NRF), funded by the Ministry of Education (grant no. NRF-2016R1A6A1A03011325)

\section{References}

1. Yang S, Chen J, Guo Z, Xu XM, Wang L, Pei XF, Yang J, Underhill CB and Zhang L: Triptolide inhibits the growth and metastasis of solid tumors. Mol Cancer Ther 2: 65-72, 2003.

2. Raab MS, Podar K, Breitkreutz I, Richardson PG and Anderson KC: Multiple myeloma. Lancet 374: 324-339, 2009.

3. Jemal A, Siegel R, Xu J and Ward E: Cancer statistics, 2010. CA Cancer J Clin 60: 277-300, 2010.

4. Kumar SK, Dispenzieri A, Lacy MQ, Gertz MA, Buadi FK, Pandey S, Kapoor P, Dingli D, Hayman SR, Leung N, et al: Continued improvement in survival in multiple myeloma: changes in early mortality and outcomes in older patients. Leukemia 28 : $1122-1128,2014$

5. Kyle RA and Rajkumar SV: Treatment of multiple myeloma: a comprehensive review. Clin Lymphoma Myeloma 9: 278-288, 2009

6 . Kyle RA: Targeted therapy of multiple myeloma. Hematology 17 Suppl 1: 125-128, 2012.

7. Anderson KC: The 39th David A. Karnofsky Lecture: bench-tobedside translation of targeted therapies in multiple myeloma. J Clin Oncol 30: 445-452, 2012.

8. Kong LY and Tan RX: Artemisinin, a miracle of traditional Chinese medicine. Nat Prod Rep 32: 1617-1621, 2015.

9. Ding GS: Important Chinese herbal remedies. Clin Ther 9: 345-357, 1987

10. Chen BJ: Triptolide, a novel immunosuppressive and anti-inflammatory agent purified from a Chinese herb Tripterygium wilfordii Hook F. Leuk Lymphoma 42: 253-265, 2001.

11. Wu R, Li Y, Guo Z, Gong J, Zhu W, Li N and Li J: Triptolide ameliorates ileocolonic anastomosis inflammation in IL-10 deficient mice by mechanism involving suppression of miR-155/SHIP-1 signaling pathway. Mol Immunol 56: 340-346, 2013.

12. Wei X, Gong J, Zhu J, Wang P, Li N, Zhu W and Li J: The suppressive effect of triptolide on chronic colitis and TNF-alpha/TNFR2 signal pathway in interleukin-10 deficient mice. Clin Immunol 129: 211-218, 2008.

13. Qiu D and Kao PN: Immunosuppressive and anti-inflammatory mechanisms of triptolide, the principal active diterpenoid from the Chinese medicinal herb Tripterygium wilfordii Hook. f. Drugs R D 4: 1-18, 2003.

14. Lin N, Liu C, Xiao C, Jia H, Imada K, Wu H and Ito A: Triptolide, a diterpenoid triepoxide, suppresses inflammation and cartilage destruction in collagen-induced arthritis mice. Biochem Pharmacol 73: 136-146, 2007.

15. Zhu W, He S, Li Y, Qiu P, Shu M, Ou Y, Zhou Y, Leng T, Xie J, Zheng X, et al: Anti-angiogenic activity of triptolide in anaplastic thyroid carcinoma is mediated by targeting vascular endothelial and tumor cells. Vascul Pharmacol 52: 46-54, 2010.

16. Banerjee S, Sangwan V, McGinn O, Chugh R, Dudeja V, Vickers SM and Saluja AK: Triptolide-induced cell death in pancreatic cancer is mediated by O-GlcNAc modification of transcription factor Sp1. J Biol Chem 288: 33927-33938, 2013.

17. Phillips PA, Dudeja V, McCarroll JA, Borja-Cacho D Dawra RK, Grizzle WE, Vickers SM and Saluja AK: Triptolide induces pancreatic cancer cell death via inhibition of heat shock protein 70. Cancer Res 67: 9407-9416, 2007.

18. Wu PP, Liu KC, Huang WW, Ma CY, Lin H, Yang JS and Chung JG: Triptolide induces apoptosis in human adrenal cancer NCI-H295 cells through a mitochondrial-dependent pathway. Oncol Rep 25: 551-557, 2011.

19. Zheng Y, Zhang WJ and Wang XM: Triptolide with potential medicinal value for diseases of the central nervous system. CNS Neurosci Ther 19: 76-82, 2013.

20. Zhao F, Chen Y, Li R, Liu Y, Wen L and Zhang C: Triptolide alters histone $\mathrm{H} 3 \mathrm{~K} 9$ and $\mathrm{H} 3 \mathrm{~K} 27$ methylation state and induces G0/G1 arrest and caspase-dependent apoptosis in multiple myeloma in vitro. Toxicology 267: 70-79, 2010.

21. Yinjun L, Jie J and Yungui W: Triptolide inhibits transcription factor NF-kappaB and induces apoptosis of multiple myeloma cells. Leuk Res 29: 99-105, 2005.
22. Chen Q, Lu Z, Jin Y, Wu Y and Pan J: Triptolide inhibits Jak2 transcription and induces apoptosis in human myeloproliferative disorder cells bearing Jak2V617F through caspase-3-mediated cleavage of Mcl-1. Cancer Lett 291: 246-255, 2010.

23. Tang J, Li ZH, Ge SN, Wang W, Mei XP, Wang W, Zhang T, Xu LX and $\mathrm{Li}$ JL: The inhibition of spinal astrocytic JAK2-STAT3 pathway activation correlates with the analgesic effects of triptolide in the rat neuropathic pain model. Evid Based Complement Alternat Med 2012: 185167, 2012.

24. Wang Z, Jin H, Xu R, Mei Q and Fan D: Triptolide downregulates Racl and the JAK/STAT3 pathway and inhibits colitis-related colon cancer progression. Exp Mol Med 41: 717-727, 2009.

25. Aggarwal BB, Sethi G, Ahn KS, Sandur SK, Pandey MK, Kunnumakkara AB, Sung B and Ichikawa H: Targeting signal -transducer-and-activator-of-transcription-3 for prevention and therapy of cancer: modern target but ancient solution. Ann N Y Acad Sci 1091: 151-169, 2006.

26. Yu H, Kortylewski M and Pardoll D: Crosstalk between cancer and immune cells: role of STAT3 in the tumour microenvironment. Nat Rev Immunol 7: 41-51, 2007.

27. Zhong Z, Wen Z and Darnell JE Jr: Stat3: a STAT family member activated by tyrosine phosphorylation in response to epidermal growth factor and interleukin-6. Science 264: 95-98, 1994.

28. Grandis JR, Drenning SD, Chakraborty A, Zhou MY, Zeng Q, Pitt AS and Tweardy DJ: Requirement of Stat3 but not Stat1 activation for epidermal growth factor receptor-mediated cell growth in vitro. J Clin Invest 102: 1385-1392, 1998.

29. Zushi S, Shinomura Y, Kiyohara T, Miyazaki Y, Kondo S, Sugimachi M, Higashimoto Y, Kanayama S and Matsuzawa Y: STAT3 mediates the survival signal in oncogenic ras-transfected intestinal epithelial cells. Int J Cancer 78: 326-330, 1998.

30. Shen Y, Devgan G, Darnell JE Jr and Bromberg JF: Constitutively activated Stat 3 protects fibroblasts from serum withdrawal and UV-induced apoptosis and antagonizes the proapoptotic effects of activated Stat1. Proc Natl Acad Sci USA 98: 1543-1548, 2001.

31. Bhattacharya S, Ray RM and Johnson LR: STAT3-mediated transcription of Bcl-2, Mcl-1 and c-IAP2 prevents apoptosis in polyamine-depleted cells. Biochem J 392: 335-344, 2005.

32. Aoki Y, Feldman GM and Tosato G: Inhibition of STAT3 signaling induces apoptosis and decreases survivin expression in primary effusion lymphoma. Blood 101: 1535-1542, 2003.

33. Yu CL, Meyer DJ, Campbell GS, Larner AC, Carter-Su C, Schwartz J and Jove R: Enhanced DNA-binding activity of a Stat3-related protein in cells transformed by the Src oncoprotein. Science 269: 81-83, 1995.

34. Schreiner SJ, Schiavone AP and Smithgall TE: Activation of STAT3 by the Src family kinase Hck requires a functional SH3 domain. J Biol Chem 277: 45680-45687, 2002.

35. Ihle JN: STATs: signal transducers and activators of transcription. Cell 84: 331-334, 1996.

36. Chim CS, Fung TK, Cheung WC, Liang R and Kwong YL: SOCS1 and SHP1 hypermethylation in multiple myeloma: implications for epigenetic activation of the Jak/STAT pathway. Blood 103: 4630-4635, 2004

37. Oka T, Ouchida M, Koyama M, Ogama Y, Takada S, Nakatani Y, Tanaka T, Yoshino T, Hayashi K, Ohara N, et al: Gene silencing of the tyrosine phosphatase SHP1 gene by aberrant methylation in leukemias/lymphomas. Cancer Res 62: 6390-6394, 2002.

38. Yu H and Jove R: The STATs of cancer - new molecular targets come of age. Nat Rev Cancer 4: 97-105, 2004.

39. Weinmann P, Gaehtgens P and Walzog B: Bcl-Xl- and Bax-alpha-mediated regulation of apoptosis of human neutrophils via caspase-3. Blood 93: 3106-3115, 1999.

40. Jin K, Mao XO, Batteur SP, McEachron E, Leahy A and Greenberg DA: Caspase-3 and the regulation of hypoxic neuronal death by vascular endothelial growth factor. Neuroscience 108: 351-358, 2001.

41. Chan EW, Cheng SC, Sin FW and Xie Y: Triptolide induced cytotoxic effects on human promyelocytic leukemia, $\mathrm{T}$ cell lymphoma and human hepatocellular carcinoma cell lines. Toxicol Lett 122: 81-87, 2001.

42. Chen YW, Lin GJ, Chia WT, Lin CK, Chuang YP and Sytwu HK: Triptolide exerts anti-tumor effect on oral cancer and KB cells in vitro and in vivo. Oral Oncol 45: 562-568, 2009.

43. Tengchaisri T, Chawengkirttikul R, Rachaphaew N, Reutrakul V, Sangsuwan R and Sirisinha S: Antitumor activity of triptolide against cholangiocarcinoma growth in vitro and in hamsters. Cancer Lett 133: 169-175, 1998. 
44. Pyatt DW, Yang Y, Mehos B, Le A, Stillman W and Irons RD Hematotoxicity of the chinese herbal medicine Tripterygium wilfordii Hook $\mathrm{f}$ in CD34-positive human bone marrow cells. Mol Pharmacol 57: 512-518, 2000.

45. Schindler C and Darnell JE Jr: Transcriptional responses to polypeptide ligands: the JAK-STAT pathway. Annu Rev Biochem 64: 621-651, 1995.

46. Hodge DR, Hurt EM and Farrar WL: The role of IL-6 and STAT3 in inflammation and cancer. Eur J Cancer 41: 2502-2512, 2005.

47. Chang Q, Bournazou E, Sansone P, Berishaj M, Gao SP, Daly L, Wels J, Theilen T, Granitto S, Zhang X, et al: The IL-6/JAK/Stat 3 feed-forward loop drives tumorigenesis and metastasis. Neoplasia 15: 848-862, 2013.

48. Quintanilla-Martinez L, Kremer M, Specht K, Calzada-Wack J, Nathrath M, Schaich R, Höfler H and Fend F: Analysis of signal transducer and activator of transcription 3 (Stat 3) pathway in multiple myeloma: Stat 3 activation and cyclin D1 dysregulation are mutually exclusive events. Am J Pathol 162: 1449-1461, 2003.

49. Zhang Q, Raghunath PN, Vonderheid E, Odum N and Wasik MA: Lack of phosphotyrosine phosphatase SHP-1 expression in malignant T-cell lymphoma cells results from methylation of the SHP-1 promoter. Am J Pathol 157: 1137-1146, 2000.
50. Depil S, Saudemont A and Quesnel B: SOCS-1 gene methylation is frequent but does not appear to have prognostic value in patients with multiple myeloma. Leukemia 17: 1678-1679, 2003.

51. Catlett-Falcone R, Landowski TH, Oshiro MM, Turkson J, Levitzki A, Savino R, Ciliberto G, Moscinski L, FernándezLuna JL, Nuñez G, et al: Constitutive activation of Stat 3 signaling confers resistance to apoptosis in human U266 myeloma cells. Immunity 10: 105-115, 1999.

52. Heere-Ress E, Thallinger C, Lucas T, Schlagbauer-Wadl H, Wacheck V, Monia BP, Wolff K, Pehamberger H and Jansen B: $\mathrm{Bcl}-\mathrm{X}(\mathrm{L})$ is a chemoresistance factor in human melanoma cells that can be inhibited by antisense therapy. Int J Cancer 99: 29-34, 2002.

53. Digicaylioglu M and Lipton SA: Erythropoietin-mediated neuroprotection involves cross-talk between Jak2 and NF-kappaB signalling cascades. Nature 412: 641-647, 2001. 